\title{
Action potential initiation in damaged axon initial segment
}

\author{
Louis Jacques ${ }^{1 *}$, Catherine E Morris ${ }^{2}$, André Longtin ${ }^{1}$, Béla Joos ${ }^{1}$ \\ From The Twenty Third Annual Computational Neuroscience Meeting: CNS*2014 \\ Québec City, Canada. 26-31 July 2014
}

The effects of physical trauma to nerve cells are of great interest in neuroscience and neuromedicine. The ion channels kinetics are affected by the trauma-induced damage to neural membrane structure. The density of affected channels is at its highest in the nodes and the axon initial segment (AIS). In this study we focus on the consequences of modifying sodium channels kinetics in the AIS to model the effect of damage. It is inspired by a similar study on damaged nodes of Ranvier [1] and by experiments done in vivo on AIS [2,3]. The AIS and the nodes of Ranvier have similar mixtures of channels, but differ in their shapes. Whereas the nodal channels are clustered at high density near a large volume of channel free low capacitance membrane the AIS is long with varying density profiles for each ion channel types. The AIS is the location for action potential (AP) initiation.

A neuron was simulated as three sections, each containing multiple compartments: the soma, the initial segment and the myelinated axon. Each compartment was modeled by the classical Hodgkin-Huxley equations using appropriate densities for each type of ion channel. The types of channels and their distributions were based on a previous study looking specifically at cortical pyramidal neurons having Nav1.2 and Nav1.6 at the AIS [4]. The kinetics were modified according to the coupled left-shift (CLS) model $[1,5]$. This model is based on observations showing that in damaged membranes $\mathrm{Na}$ channel kinetic midpoints shift leftward to more hyperpolarized values, effectively rendering the channels hypersensitive. In this study we explore the impact of CLS on the generation of APs in the AIS. The simulation includes NaK-ATPase pumps and inner and outer ion concentrations are monitored. With increased damage, the greater ionic conductance at rest

\footnotetext{
* Correspondence: ljacq059@uottawa.ca

${ }^{1}$ Department of Physics, University of Ottawa, Ottawa, Ontario, Canada, K1N $6 \mathrm{~N} 5$

Full list of author information is available at the end of the article
}

potential (Na-leak conductance) puts greater strain on the pumps. In the case of a single node, hyperexcitability, tonic firing, burst firing, or inexcitability is observed for increasing values of CLS.

We explored the effect of damage on the initiation and propagation of APs during repeated stimuli which deplete concentration gradients. Our model allows the investigation of the effect of CLS on the location and duration of the initiation and the threshold duration of Ap-initiatingcurrents. We find that the current threshold for action potential initiation decreases with increased damage or decreased length of the AIS.

\section{Authors' details}

'Department of Physics, University of Ottawa, Ottawa, Ontario, Canada, K1N 6N5. ${ }^{2}$ Neurosciences, Ottawa Hospital Research Institute, Ottawa, Ontario, Canada, K1H 8M5.

Published: 21 July 2014

\section{References}

1. Boucher PA, Joós B, Morris CE: Coupled left-shift of Nav channels: modeling the $\mathrm{Na}$--loading and dysfunctional excitability of damaged axons. J Comput Neurosci 2012, 33(2):301-319.

2. Schafer DP, Jha S, Liu F, McCullough LD, Rasband MN: Disruption of the axon initial segment cytoskeleton is a new mechanism for neuronal injury. J Neurosci 2009, 29(42):13242-13254.

3. Baalman KL, Cotton JR, Rasband SN, Rasband MN: Blast wave exposure impairs memory and decreases axon initial segment length. Journal of Neurotrauma 2013

4. Hu W, Tian C, Li T, Yang M, Hou H, Shu Y: Distinct contributions of Nav1.6 and Nav1.2 in action potential initiation and backpropagation. Nat Neurosci 2009, 12(8):996-1002.

5. Wang JA, Lin W, Morris T, Banderali U, Juranka PF, Morris CE: Membrane trauma and $\mathrm{Na}+$ leak from Nav1.6 channels. Am J Physiol Cell Physiol 2009, 297(4):C823-C834.

doi:10.1186/1471-2202-15-S1-P135

Cite this article as: Jacques et al.: Action potential initiation in damaged axon initial segment. BMC Neuroscience 2014 15(Suppl 1):P135.
C Biomed Central (c) 2014 Jacques et al; licensee BioMed Central Ltd. This is an Open Access article distributed under the terms of the Creative Commons Attribution License (http://creativecommons.org/licenses/by/4.0), which permits unrestricted use, distribution, and reproduction in any medium, provided the original work is properly cited. The Creative Commons Public Domain Dedication waiver (http:// creativecommons.org/publicdomain/zero/1.0/) applies to the data made available in this article, unless otherwise stated. 